\section{DA-RT Workshop Held in Washington, DC}

Tr n March 2015, APSA, the Center for Political Studies at the University of Michigan, and the Center for Qualitative and Multi-Method Inquiry at Syracuse University, cosponsored "Data Sharing and Research Transparency in the Social Sciences: The Role of Scholarly Associations" in Washington, DC. This workshop on data access and research transparency (DA-RT) brought together leaders from a diverse set of social science-oriented scholarly associations. A number of forward-looking academic publishers also sent representatives. The workshop highlighted the role scholarly associations have played, and can play, in using greater commitments to data sharing and research transparency to increase the credibility and legitimacy of their members' scholarly work.

\section{BACKGROUND}

For many years, and in many disciplines, the rewards to authors for publishing evidence-based knowledge claims were hardly increased at all by their also providing comprehensive information about how those claims were produced. These practices have hindered readers' ability to truly understand or evaluate many evidence-based claims. Because transparent research is more credible and more legitimate, new opportunities for transparency promise substantial benefits for the advancement of knowledge. In addition, shared data provide public goods that pay extraordinary dividends for entire research communities and society at large. For these reasons, social scientists from a

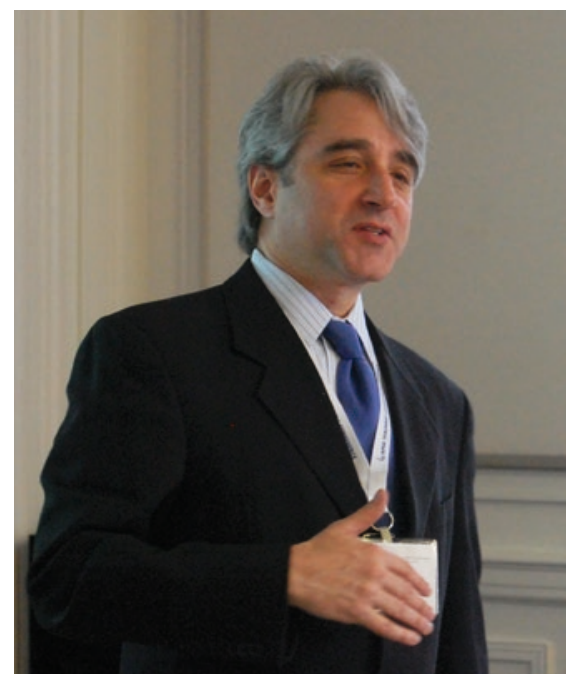

Arthur Lupia, one of the workshop oganizers, discusses public perceptions of the value of social sciences. wide variety of epistemological traditions are developing and implementing new standards that increase credibility and give readers improved abilities to correctly interpret evidence-based claims. Scholarly associations have a unique potential to promote such efforts and the workshop focused on how they could hasten and extend recent progress.

\section{WORKSHOP HIGHLIGHTS}

- An introduction by Steven Rathgeb Smith on APSA's experiences in advancing transparency, including the Association's leadership of the DA-RT initiative.

- A discussion led by Arthur Lupia on how transparency improves the public worth of social science, and on how efforts to increase data sharing and research transparency can help professional associations achieve their core missions and add value to membership in their organizations.

- A presentation by Colin Elman on how political scientists found a shared language to discuss openness, despite their different ontological and epistemological commitments.

- Arthur Lupia mapped out the progress of the DA-RT project, and explained how it motivated a group of leading journal editors in political science to develop and agree to a joint statement on research transparency. John Ishiyama, lead editor of the American Political Science Review, discussed the APSR's decision to sign the joint statement, and its subsequent efforts to implement new policies and provide guidance to its future authors.

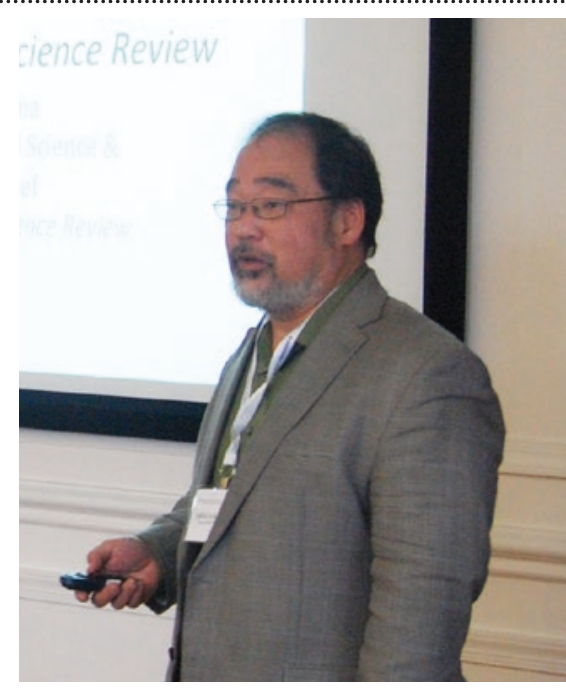

John Ishiyama speaks about the leading initiatives taken by the editors of APSR regarding data access and research transparency. (Photos courtesy of Drew Meadows)

- Leaders of other scholarly associations with strong connections to political science described parallel efforts in their organizations. Brian Pollins described the International Studies Association's early encouragement of research transparency. Gary Langer of Langer Research Associates also examined how a range of survey-based organizations succeeded at increasing transparency. Langer highlighted the importance of stakeholder buy-in, and the importance of encouraging and even incentivizing participation in DA-RT.

The workshop closed with discussions of how professional associations can further collaborate to increase the kinds of credibility and legitimacy to which so many of their members aspire.

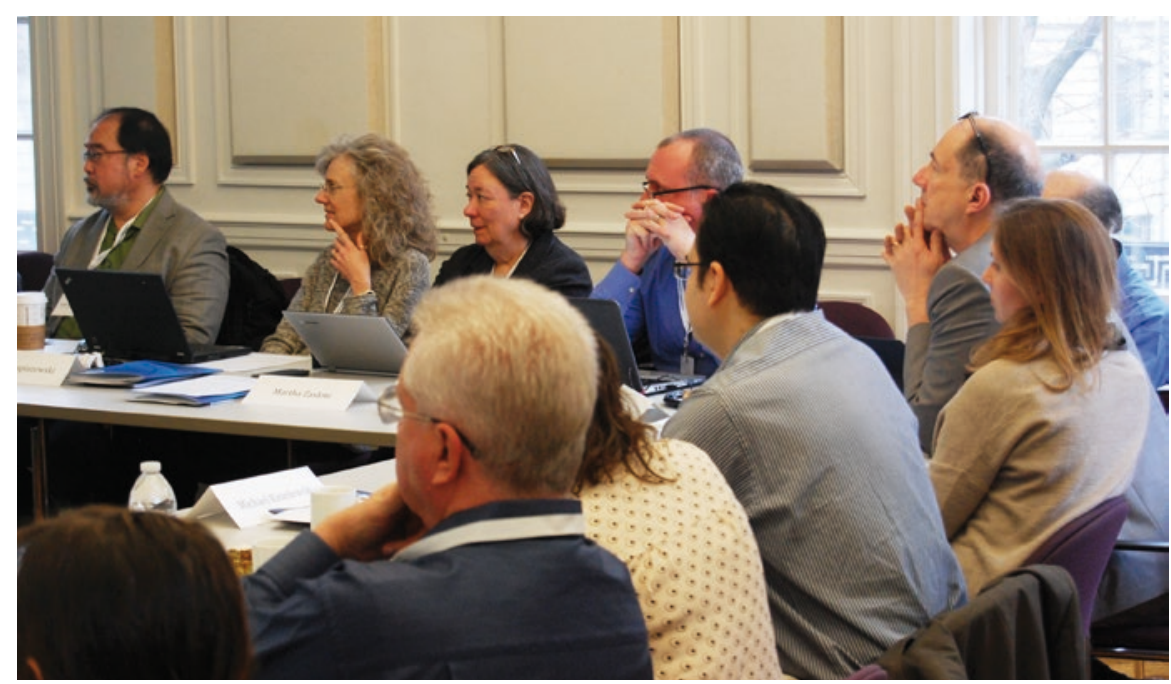

Workshop attendees listen intently during one of the presentations. The presenters-as well as the input from various attendees between sessions-provided compelling insight into the future of research and publishing in the social sciences. 